\title{
Strategi Dalam Meningkatan Pendidikan Wajib Belajar 12 Tahun di Kabupaten Demak
}

\section{Strategies in Improving 12 Years of Compulsory Education in Demak Regency}

\author{
Dewi Sintha, Hardi Warsono, Agustin Rina Herawati, Retno Sunu Astuti \& \\ Teuku Afrizal*.
}

\author{
Magister Administrasi Publik, Fakultas Ilmu Sosial dan Ilmu Politik \\ Universitas Diponegoro, Indonesia
}

Diterima: 14 Mei 2021 Direview: 14 Mei 2021; Disetujui: 06 Agustus 2021 *Coresponding Email: teukurian@lecturer.undip.ac.id

Penelitian ini bertujuan untuk meneliti strategi dalam meningkatkan Pendidikan wajib belajar 12 tahun. Penelitian ini dilakukan untuk memperoleh informasi terkait dukungan pemerintah dalam pelaksanaan pendidikan wajib belajar 12 tahun di kabupaten Demak. Ini termasuk memamahami faktor-faktor penyebab anak putus sekolah dari faktor internal dan faktor eksternal. Faktor internal disebabkan minimnya pendapatan keluarga dan rendahnya tingkat pendidikan orangtua. Faktor eksternal disebabkan oleh faktor lingkungan. Berdasarkan kepada pendekatan kualitatif deskriptif penelitian ini dilaksanakan di Kabupaten Demak. Pengumpulan data dilakukan melalui observasi dan studi pustaka. Hasil penelitian menunjukkan dukungan pemerintah pada pelaksanaan wajib belajar 12 tahun di Kabupaten Demak dengan pemberian "biasiswa ayo sekolah kembali" mulai pendidikan dasar hingga pendidikan menengah atas biasiswa tersebut diberikan kepada siswa kurang mampu secara ekonomi guna untuk meningkatkan partisipasi siswa dalam bersekolah.

Kata Kunci: Strategi; Peningkatan; Wajib Belajar 12 Tahun; Faktor Ekonomi; Pendidikan Rendah

\begin{abstract}
This study aims to examine strategies in improving the 12 year compulsory education. This research was conducted to obtain information related to government support in the implementation of 12 year compulsory education in Demak district. This includes understanding the factors that cause children to drop out of school from internal factors and external factors. Internal factors are due to the lack of family income and the low level of parental education. External factors are caused by environmental factors. Based on the descriptive qualitative approach this research was carried out in Demak Regency. Data collection was carried out through observation and literature study. The results showed that government support for the implementation of the 12 year compulsory education in Demak Regency with the provision of "let's go back to school" starting from primary education to senior secondary education is given to economically disadvantaged students in order to increase student participation in school.

Keywords: Strategy; Enhancement; 12 Year Compulsory Education; Economic Factors; Low education
\end{abstract}

How to Cite: Sintha, D., Warsono, H., Herawati, A.R., Astuti, R.S., \& Afrizal, T. (2021). Strategi Dalam Meningkatan Pendidikan Wajib Belajar 12 Tahun di Kabupaten Demak. Journal of Education, Humaniora and Social Sciences (JEHSS). 4 (2): 686-694. 


\section{PENDAHULUAN}

Pendidikan adalah suatu kegiatan yang menyangkut kehidupan sosial budaya masyarakat dan bangsa. Pendidikan merupakan hal yang sangat penting dan vital dalam membangun dan mengembangkan kualitas warganegara dimana pendidikan dapat menjadi pilar kehidupan masa kini dan yang akan datang terhadap keberlangsungan suatu bangsa. Apa yang dilakukan dalam kegiatan pendidikan untuk membangun kualitas warganegara dan bangsa dapat dilihat dari kebijakan, perencanaan dan pelaksanaan kurikulum. Salahsatu faktor utama keberhasilan pembangunan suatu negara terletak pada tersedianya sumber daya manusia yang bermutu, peninkatan mutu tersebut berada pada pembangunan bidang pendidikan.oleh karena itu pendidikan merupakan aspek yang sangat penting dalam pembangunan suatu negara. (Saripudin, 2005)

Dalam undang undang No 20 tahun 2003 program pendidikan yang harus di ikuti oleh warga Negara Indonesia yaitu wajib belajar 12 tahun, adapun Kebijakan perintah kabupaten Demak telah tertuang dalam belajar 12 tahun bagi seluruh masyarakat usia 16-18 tahun. Peraturan tersebut menyatakan bahwa warga negara diwajibkan mengikuti wajib belajar 12 tahun atau sampai jenjang pendidikan menengah atas. Masih di temukannya anak putus sekolah dan anak menjadikan dalam kasus ini pemerintah bekerja keras untuk meminimalisir angka anak putus sekolah, perlunya strategi,usaha, dan langkah dari pemerintah yang matang agar tidak berdampak dalam segi penurunan kualitas sumber daya manusia di kabupaten Demak.

Kajian Teoritik

Kebijakan Publik

Menurut Tilaar (2009) kebijakan pendidikan adalah keseluruhan proses dan hasil perumusan langkah-langkah strategis pendidikan yang merupakan penjabaran dari visi dan misi pendidikan, dalam rangka tercapainya tujuan pendidikan dalam suatu masyarakat untuk suatu waktu kurun tertentu. Kebijakan mengarah pada tujuan yang diusulkan oleh seseorang, kelompok atau pemerintah dalam lingkungan tertentu sehubungan dengan adanya hambatan-hambatan tertentu seraya mencari peluang-peluang untuk mencapai tujuan atau mewujudkan sasaran yang diinginkan.

Pengertian Wajib Belajar

Wajib belajar merupakan program pendidikan yang harus diikuti oleh warga Negara Indonesia atas tanggung jawab Pemerintah dan Pemerintah Daerah (UU Nomor 20 Tahun 2003 tentang Sistem Pendidian Nasional). Menurut (Soedijarto, 2008) pengertian wajib belajar sebagai terjemahan dari "Compulsary Education" merujuk pada suatu kebijakan yang mengharuskan warga negara dalam usia sekolah untuk mengikuti pendidikan sekolah sampai pada jenjang tertentu dan pemerintah memberikan dukungan sepenuhnya agar peserta wajib belajar dapat mengikuti pendidikan. Program wajib belajar 12 tahun merupakan kewajiban bagi setiap warga negara yang telah tamat SMP atau sederajat dengan batas usia 16-18 tahun untuk mengikuti pendidikan SMA atau sederajat sampai tamat (Aulia, 2012).

Pendidikan merupakan usaha yang sengaja diadakan baik langsung maupun tidak langsung untuk membantu anak mencapai pengembanganya yang menyangkut praktik, belajar dan mengajar ( SA Bratanata).untuk mencapai mutu pendidikan tersebut maka di keluarkannya kebijakan pendidikan wajib 12 tahun yang berfungsi mengupayakan perluasan dan pemerataan kesempatan memperoleh pendidikan yang bermutu bagi setiap warga negara Indonesia. (PP nomor 47 Tahun 2008 tentang wajib belajar).

Adapun model untuk memperkaya pemahaman tentang berbagai strategi pemerintah Kabupaten Demak dalam peningkatan wajib belajar 12 tahun di kabupaten Demak maka pada bagian ini ada tiga teori implementasi kebijakan yang dapat dijadikan sebagai landasan pijak dalam penelitian ini menurut Model Tachjan (Tachjan, 2006) menjelaskan bahwa ada beberapa unsur yang mutlak harus ada dalam implementasi sebuah kebijakan yaitu:

Unsur pelaksana. 
Pelaksanaan kebijakan merupakan pihak-pihak yang menjalankan baik organisasi atau perorangan untuk bertanggung jawab dalam memperoleh pelaksanaan dan pengawasan dari proses implementasi tersebut.

Adanya program yang dilaksanakan.

Kebijakan publik tidak mempunyai arti penting tanpa adanya tindakan nyata yang dilakukan dengan berbagai program atau kegiatan.

Kelompok sasaran.

Kelompok sasaran adalah sekelompok orang atau organisasi dalam masyarakat yang akan menerima barang atau jasa yang akan dipengaruhi perilakunya oleh kebijakan.

Yenny Merinatul Hasanah, Cepi Safruddin Abdul Jabar, Evaluasi program wajib belajar 12 tahun pemerintah daerah Kota Yogyakarta. Penelitian ini bertujuan mengevaluasi: (1) pelaksanaan program (2) pencapaian tujuan program, dan(3) hambatan-hambatan pelaksanaan program wajibbelajar 12 tahun di Kota Yogyakarta. Penelitian ini merupakan penelitian evaluasi dengan menggunakan pendekatan kualitatif. Model evaluasi yang digunakan adalah discrepancy evaluation program. Hasil penelitian program wajib belajar 12 tahun di Kota Yogyakarta bukan Compulsory Education, tetapi lebih merupakan Basic Education Program (BEP) yang didasari Universal Besic Education (UBE) yang pada hakekatnya berarti penyediaan akses yang sama untuk mengikuti pendidikan dasar terhadap anak. Hasil penelitian menunjukkan bahwa (1) pelaksanaan Program Wajib Belajar 12 Tahun: (a) kecukupan tanaga pendidik belum terpenuhi pada jenjang SD, (b) ketersediaan sarana prasarana belum terpenuhisecara keseluruhan, dan(c) ketersediaan pembiayaan pendidikan sudah terpenuhi. (2) pencapaian tujuan program wajib belajar 12 tahun: (a) meningkatkan Angka Partisipasi Sekolah (APS), (b) mengurangi Angka Putus Sekolah (APS), (c) meningkatkan Angka Melanjutkan (AM), (d) program wajib belajar sudah dapat meningkatkan anak lulus minimal SMA/SMK dan sederajat, dan (e) terwujudnya perluasan akses dan pemerataan pendidikan untuk semua. (3) Hambatan-hambatan Program Wajib Belajar 12 Tahunadalah: (a)rendahnya daya beli/tingkat partisipasi masyarakat terhadap pembiayaan pendidikan, (b) rendahnya minat anak dan kesadaran orang tua kurang terhadap pentingnya pendidikan untuk masa depan, (c) masih adanya anak putus sekolah di Kota Yogyakarta (d) sosialisasi program wajib belajar 12 tahun kurang maksimal, dan (e) tidak tepatnya subsidi (KMS) pemerintah Kota Yogyakarta.

Desentralisasi Kebijakan Pendidikan (Studi Tentang Pelaksanaan Wajib Belajar 12 Tahun Di Kota Surabaya Pada Tingkat Pendidikan Menengah dan Kejuruan) Sitta Aulia. Penelitian ini bertujuan untuk memperoleh informasi tentang dukungan pemerintah kota Surabaya dan dampaknya dalam pelaksanaan pendidikan wajib belajar 12 tahun di Kota Surabaya. Pendidikan menjadi tanggung jawab pemerintah daerah merupakan konsekuensi dari adanya desentralisasi pendidikan. Pelaksanaan pendidikan darisentralisasi ke desentralisasi membuat pemerintah daerahmemiliki kewenangan yang nyata dan luas dalam hal perencanaan, pelaksanaan, dan pembuatan kebijakan pendidikan di wilayahnya. Penelitian ini dilakukan di lima sekolah menegah dan kejuruan yang ada di Surabaya, dengan sumber data dinas pendidikan kota Surabaya, pengamat pendidikan, kepala sekolah dan guru di sekolah menengah dan kejuruan. Pengumpulan data dilakukan melalui studi dokumentasi, observasi, dan wawancara. Data yang diperoleh dianalisis secara deskriptif kualitatif. Hasil penelitian menunjukkan: 1) Dukungan pemerintah pada pelaksanaan wajib belajar 12 tahun di Surabaya dengan pemberian Biaya Operasional Pendidikan Daerah (BOPDA) mulai pendidikan dasar hingga pendidikan menengah negeri danHibah BOPDA pada sekolah swasta; 2) Pelaksanaan program BOPDA berdampak postif pada peningkatkan akses pendidikan untuk masyarakat kota Surabaya dan berdampak adanya kuota bagi masyarakat luar kota Surabaya; 3) Dampak BOPDA pada pelaksanaan pendidikan di tingkat sekolah menengah dan kejuruan berpengaruh pada manajemen pelaksanaan ditingkat sekolah, antara lain: kebijakan sekolah dalam hal pembiayaan, kondisi sarana dan prasarana

Program Implementasi Wajib Belajar 12 Tahun Di Provinsi Dki Jakarta (Studi Kota Administrasi Jakarta Timur), Oleh: Welly Kusuma Wardani Angka angka partisipasi mentah (APK) pada SMU dan SMK di DKI Jakarta tinggi, pimpin Pemprov DKI Jakarta Pemerintah mengambil kebijakan untuk mengatasi hal tersebut. Kebijakan tersebut adalah wajib belajar 12 tahun yang 6.8. http://mahesainstitute.web.id/ojs2/index.php/jehss 688 
diatur dalam Peraturan Daerah (Perda) Provinsi DKI Jakarta No. 8 tahun 2006 tentang Sistem Pendidikan. Kota Administrasi Jakarta Timur merupakan puncak dari Daftar antara Pemerintah Kota di Jakarta lainnya pada siswa SMU dan SMK jumlah siswa putus sekolah sebanyak 1.131 siswa. Oleh karena itu dalam penelitian ini penulis akan memfokuskan pada pelaksanaan program studi wajib belajar 12 tahun di Pemerintah Kota Jakarta Timur, pelaksanaan program ini bertujuan untuk meningkatkan angka partisipasi mentah (APK) dan menurunkan angka putus sekolah di Ibukota Jakarta. Penelitian ini menggunakan pendekatan kualitatif deskriptif dan metode pengumpulan datanya adalah dokumentasi dan wawancara. Subjek penelitian ini adalah Dinas Pendidikan Provinsi DKI Jakarta, Dinas Pendidikan Pemerintah Kota Jakarta Timur Tengah, Bagian Sekolah Negeri, dan Pendidikan Menengah. Analisis pelaksanaan pada program ini menunjukkan bahwa berhasil tidaknya program wajib belajar 12 tahun pada tahun ini. benar-benar ditentukan oleh organisasi implementasi dan garis depan birokrat. Hal ini disebabkan karena mereka mempunyai kewenangan untuk menjalankan program ini dan berurusan langsung dengan kelompok sasaran. Ternyata pelaksanaan program sudah cukup baik berdasarkan struktur dan tugas yang dimiliki, mekanisme kerja atau koordinasi, sumber daya manusia, dan seluruh sumber daya keuangan yang ada di organisasi. Namun terdapat beberapa kendala yang masih menghambat pencapaian program adalah kurangnya sosialisasi terhadap target, keterlambatan penyaluran dana setiap awal tahun, serta kurangnya keterlibatan organisasi masyarakat dalam program ini. Penulis menyarankan agar kendala yang ada selama ini dapat dipertimbangkan dan diselesaikan oleh Pemerintah DKI Jakarta khususnya untuk penyelenggaraan organisasi. Kemudian penelitian selanjutnya dapat meneliti program ini dalam hal evaluasi kebijakan secara keseluruhan baik masukan, proses, maupun hasil.

Dukungan terhadap pelaksanaan wajib belajar 12 tahun dengan "Biasiswa ayo sekolah kembali" harus diiringi dengan meningkatkan kualitas management di tingkat sekolah dalam laksanakannya selain itu pentingnya sosialisasi terkait program - program dukungan pemerintah kepada masyarakat terkait pentingnya pendidikan harus lebih ditingkatkan. contoh di buatkannya ruang informasi khusus yang di dalamnya memuat tentang program- program yang di galakkan pemerintah dalam upaya peningkatan pendidikan, informasi mengenai mutu pendidikan baik peserta didik maupun tenaga pendidik yang bekerja sama dengan wali murid dalam hal pengawasan sehingga menarik minat orang tua untuk mensekolahkan anak - anaknya.

Tujuan dalam penelitian ini adalah untuk mengetahui strategi dalam menerapkan program wajib belajar 12 tahun yang berada di Kabupaten Demak.

\section{METODE PENELITIAN}

Pendekatan dan Jenis Penelitian

Data diambil dengan menggunakan wawancara, observasi dan dokumentasi dengan subyek penelitian adalah: 1) Sekretaris Dinas Pendidikan Kabupaten Demak; 2) Kepala bidang pendidikan dasar dan menengah Dinas Pendidikan Kabupaten Demak; 3) Hal ini dilakukan untuk mengetahui bagaimana strategi pemerintah dalam meningkatkan partisipasi siswa terhadap program wajib belajar 12 tahun di Kabupaten Demak.

Data dan Sumber Data

Penelitian ini merupakan penelitian deskriptif kualitatif sumber data Jenis data dalam penelitian ini terdiri dari data primer yaitu dilakukan melalui sumber dari wawancara. Data yang diperoleh dianalisis secara deskriptif kualitatif. Data sekunder dalam penelitian ini yaitu, berupa arsip- arsip dokumen tentang pelaksanaan program wajib belajar 12 tahun yang diperoleh dari Badan Pusat Statistik dan Dinas Pendidikan Kabupaten Demak. Kemudian dilanjutkan dengan observasi di lapangan dan pengambilan dokumentasi.

\section{HASIL DAN PEMBAHASAN Pelaksanaan Pendidikan}


Pendidikan Pelaksanaan wajib belajar pada satuan pendidikan adalah tanggung jawab pimpinan sekolah. Sekolah menerima peserta didik dari lingkungan sekolah sesuai dengan daya tampung serta melaksanakan wajib belajar yang bermutu dan memenuhi standar nasional pendidikan.

Program

Kebijakan wajib belajar 12 tahun ini merupakan kelanjutan dari program wajib belajar 9 tahun yaitu program pada tahun 2005. Adanya kebijakan ini bertujuan untuk meningkatkan anak usia sekolah. Upaya pemerintah dalam melaksanakan program wajib belajar 12 tahun sejalan dengan visi misi pemerintah kabupaten demak dalam upaya memperkuat tata kelola pemerintahan yang baik, meningkatkan sumber daya manusia, serta mengurangi kemiskinan dan pengangguran.

Misi tersebut juga di dukung dengan program unggulan Pemerintah dengan meningkatkan kualitas dan aksebilitas pelayanan pendidikan yaitu:

1. meningkatkan kapasitas tanaga pendidik

2. ajang/lomba krativitas guru dan siswa

3. adanya biasiswa bagi masyarakat miskin

4. literasi berbasis inklusi sosial

5. adanya taman baca integrative

Program wajib belajar 12 tahun di kabupaten Demak bertujuan untuk meningkatkan akses pendidikan. Dalam strategi tersebut pemerintah kabupaten demak mengalokasikan pendanaan sebesar $20 \%$ yang bersumber dari anggaran APBN, selain itu upaya pemerintah kabupaten demak melalui program program pendukung dalam meningkatan partisipasi siswa, salahsatunya adamya program biasiswa ayo sekolah kembali yang di peruntukkan untuk masyarakat kurang mampu dalam segi ekonomi serta masyarakat putus sekolah yang dikarenakan seperti akses yang tidak terjangkau menuju sekolah, putus sekolah akibat bencana alam, menikah, karena bekerja, tidak mempunyai akta kelahiran, anak yang berhadapan dengan hukum, anak trauma akibat mengalami kekerasan di sekolah, korban pemerkosaan, maupun di karenakan berkebutuhan khusus.

Sasaran

Sasaran Wajib Belajar 12 Tahun dalam pelaksanaan Program wajib belajar 12 tahun di Kabupaten Demak. Adapun yang menjadi sasaran program wajib belajar 12 tahun adalah masyarakat yang usia 7-18 tahun yang ada di Kabupaten Demak.

Adapun data data tingkat partisipasi dalam tingkat pendidikan di Provinsi Jawa Tengah tahun 2020/2021 sebagai berikut : 
Vol 4, No. 2, November 2021: 686-694

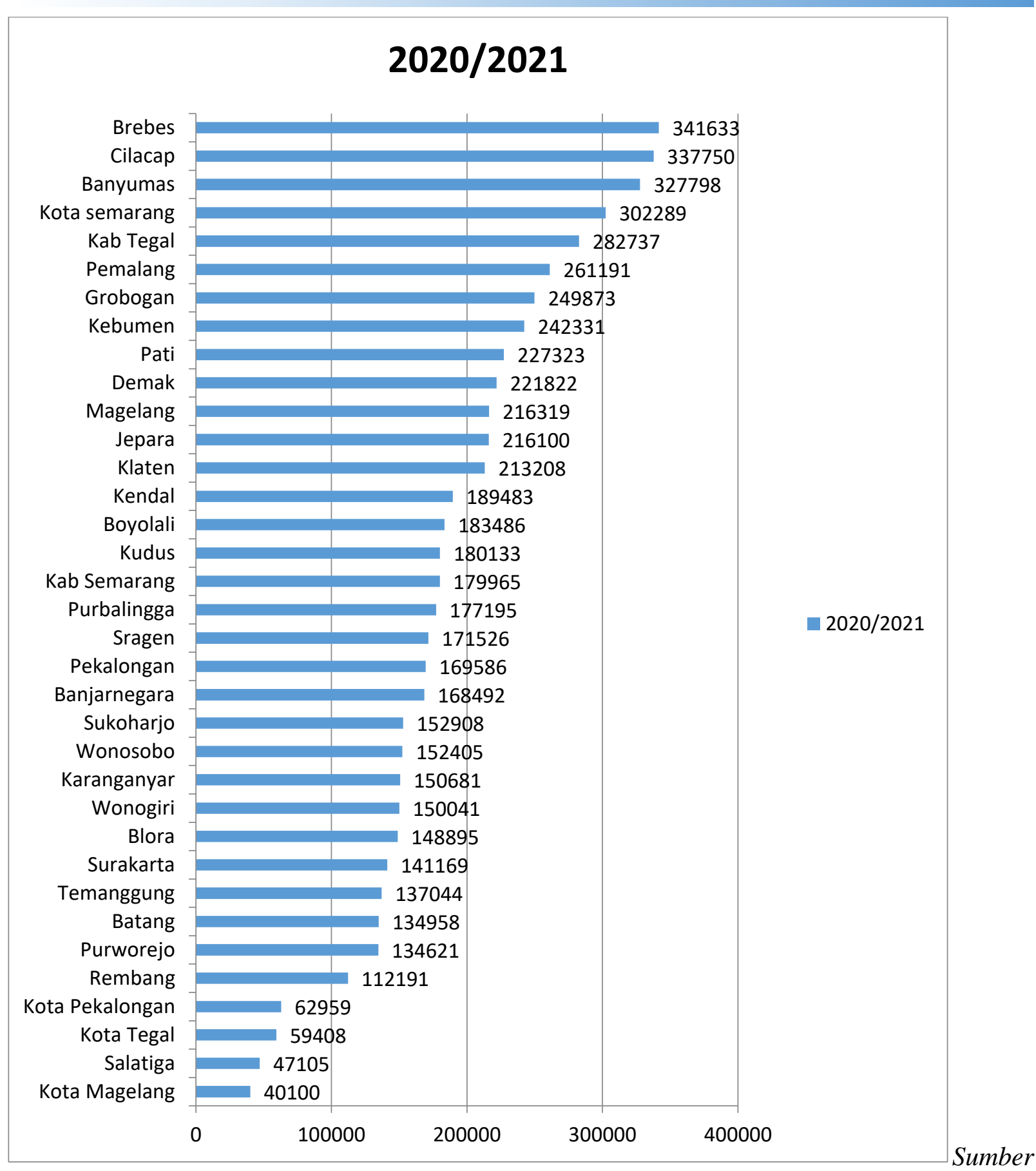

: Provinsi Jawa Tengah Dalam Angka 2021

Dari data Provinsi Jawa Tengah dalam angka 2021 dari 35 kota/kabupaten, tingkat partisipasi siswa dalam pendidikan tertinggi adalah Kabupaten Brebes dengan partisipasi siswa 341.633 siswa, sedangkan Kabupaten Demak sendiri menempati urutan ke-10 dari tingkat provinsi yaitu sebanyak 221.882 siswa yang bersekolah dari tingkat sekolah dasar (SD) sampai dengan sekolah atas (SMA), dan partisipasi pendidikan terendah yaitu Kota Magelang dengan jumlah partisipasi siswa bersekolah sebanyak 40.100 siswa.

Tingkat Partisipasi siswa bersekolah di Kabupaten Demak 2020/2021

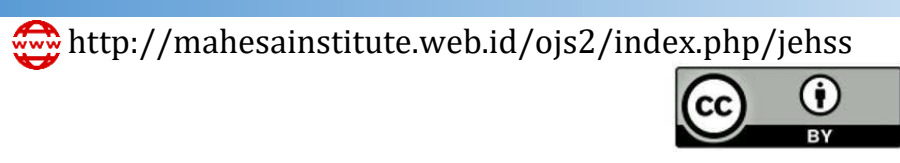

This work is licensed under a Creative Commons Attribution 4. 


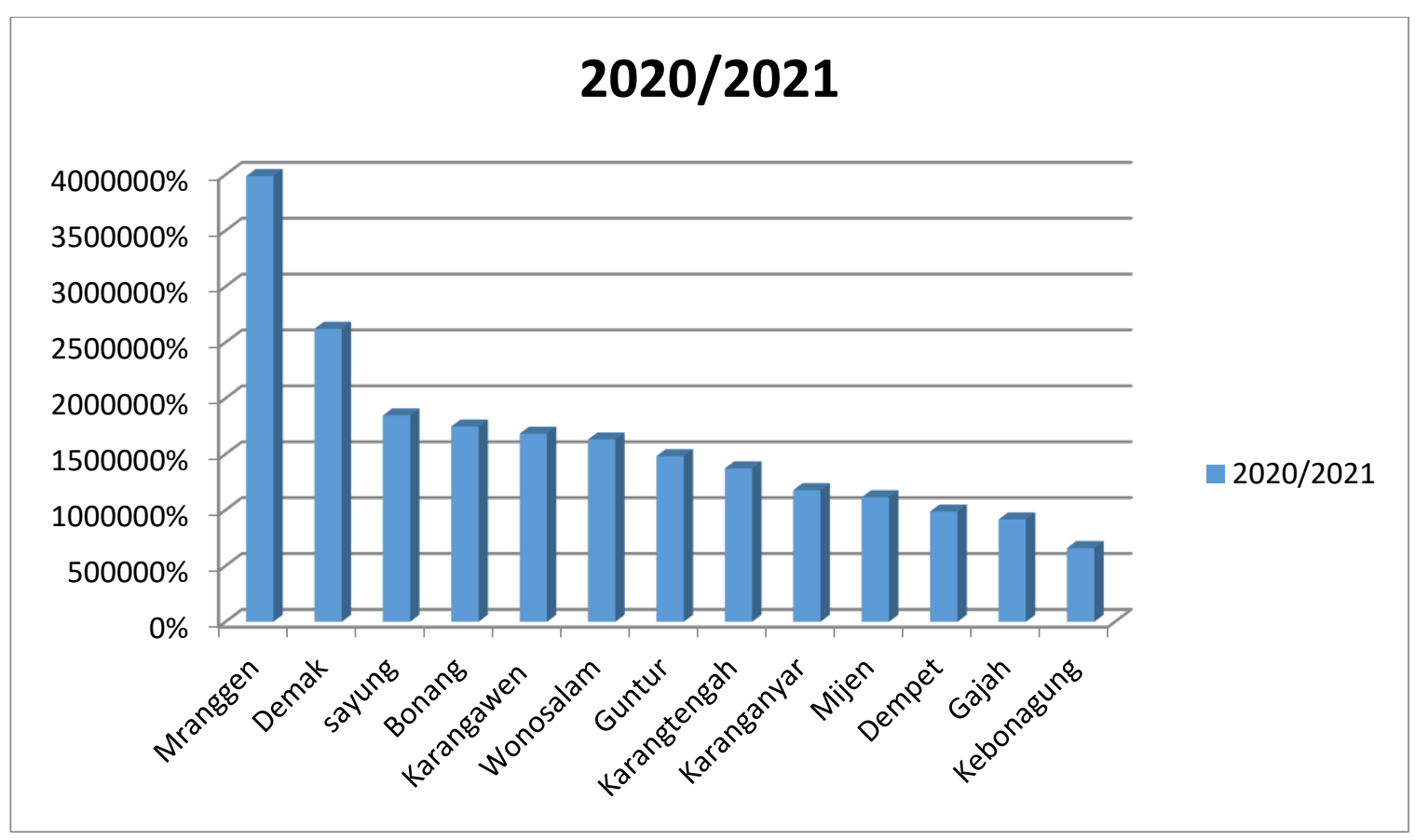

Sumber : Kabupaten Demak dalam Angka 2021

Dari 14 kecamatan yang berada di kabupaten Demak, Kecamatan kebonagung menempati posisi tingkat partisipasi terendah. Jumlah penduduk menurut rasio usia 5-19 tahun yang ada di kebonagung sebanyak 286.673 anak, namun jumlah siswa yang bersekolah hanya tahun 2020/2021 sebanyak 67.941 siswa. Dan yang tidak bersekolah sebanyak 218.731 anak.

Banyak nya faktor yang menyebabkan anak tidak sekolah sekolah di antaranya

\begin{tabular}{|l|l|l|l|}
\hline Pendidikan yang di tamatkan & Bekerja & Pengangguran & Jumlah Angkatan Kerja \\
\hline Lulusan SD & 236.479 & 7.563 & $\mathbf{2 4 4 . 0 4 2}$ \\
\hline Lulusan SMP & 133.829 & 9.845 & $\mathbf{1 4 3 . 6 7 4}$ \\
\hline Lulusan SMA & 163.236 & $\mathbf{2 4 . 4 6 4}$ & $\mathbf{1 8 7 . 7 0 0}$ \\
\hline Lulusan Sarjana & 41.058 & 3.418 & 44.476 \\
\hline
\end{tabular}

Sumber : Kabupaten Demak dalam Angka 2021

Penduduk usia kerja adalah penduduk yang berumur 15 tahun ke atas.sedangkan Angkatan kerja adalah penduduk usia kerja (15 tahun ke atas) yang bekerja, punya pekerjaan namun sementara tidak bekerja, dan pengangguran.

Kabupaten Demak sendiri dari jumlah penduduk sebanyak 1.203 .956 jiwa, adapun penduduk yang tidak bekerja/pengangguran di usia 15 tahun keatas sebanyak 45.290 jiwa yang terdiri dari lulusan SD yang bekerja pada tahun 2020 sebanyak 574.602 orang Sebaran penduduk yang bekerja paling banyak berpendidikan kurang dari sama dengan Sekolah Dasar (SD) sebesar 41,16 persen, sedangkan lulusan Perguruan Tinggi hanya sebesar 7,15 persen. Minimnya tingkat pendikan sangat berpengaruh terhadap pendapatan pendapatan orang tua yang minim mengakibatkan banyaknya masalah anak tidak bersekolah, tingkat perekonomian keluarga pada kenyataannya merupakan salah satu aspek penghambat kesempatan proses pendidikan. Orang tua berperan penting dalam hal pendidikan khususnya terhadap kelanjutan pendidikan anak ke jenjang yang lebih tinggi. selain itu pendidikan orang tua yang rendah menyebabkan kurangnya pemahaman mereka tentang pentingnya pendidikan bagi anak. Sehingga orang tua tidak serius lebih memilih anaknya untuk tidak melanjutkan sekolah daripada bekerja. 
Strategi Kabupaten Demak dalam menerapkan program wajib belajar 12 tahun dalam implimentasi pemerintah kabupaten Demak mengalokasikan pendanaan pendidikan sebesar 20 $\%$ dari anggaran APBD dan APBN. Anggaran pendidikan tersebut untuk meningkatkan partisipasi dan kompetensi siswa.

Program partisipasi siswa di antaranya melalui program biasiswa ayo sekolah kembali, adanya Program Ayo Sekolah Kembali di kabupaten Demak Program "Ayo Sekolah Kembali" diharapkan dapat menuntaskan penanganan anak tidak sekolah (ATS) di Kabupaten Demak. Dalam memenuhi standar minimal pemerintah kabupaten Demak, sudah mengalokasikan anggaran anak tidak sekolah melalui Anggaran Pendapatan dan Belanja Daerah (APBD). Hal itu untuk membantu masyarakat kurang mampu dalam segi ekonomi agar bisa bersekolah kembali. alokasi sesuai jenjang pendidikan paket $A$, paket $B$, dan paket $C$.

Melalui program Ayo Sekolah Kembali, diharapkan dapat menuntaskan penanganan anak tidak sekolah (ATS) dan anak berisiko putus sekolah (ABPS) penanganan dilakukan berdasarkan penyebabnya. Untuk anak putus sekolah dengan penyebab karena ekonomi, Pemkab Demak menyediakan beasiswa Ayo Sekolah Kembali, dengan rincian jenjang PAUD sebesar Rp750 ribu per orang, SD Rp 1 juta per orang, SMP Rp1,5 juta per orang, dan SMA Rp 2 juta perorang. sementara peningkatan sarana dan prasarana sekolah melalui pembangunan unit sekolah baru, renovasi sekolah, penyediaan sarana dan prasarana pembelajaran seperti praktikum dan teknologi informasi.

\section{DAFTAR PUSTAKA}

Journal Manajemen Peningkatan Mutu Pendidikan. Muhammad Fadhli. Institut Agama Islam Negeri (Iain) Lhokseumawe

Jurnal Ekonomi \& Pendidikan, Basrowi Dan Siti Juariyah, Analisis Kondisi Sosial Ekonomi Dan Tingkat Pendidikan Masyarakat Desa Srigading, Kecamatan Labuhan Maringgai, Kabupaten Lampung Timur Volume 7 Nomor 1, April 2010

Journal Penelitian Pendidikan Geografi, Wa Ode Sulvia, La Ode Nursalam, Faktor Penyebab Rendahnya Tingkat Pendidikan Masyarakat Di Desa Maabholu Kecamatan Loghia Kabupaten Muna, Volume 5 No. 1 Januari 2020

Journal Nevy Farista Aristin, Faktor-Faktor Yang Berpengaruh Terhadap Anak Putus Sekolah Tingkat Sekolah Menengah Pertama (Smp) Di Kecamatan Bondowoso, Universitas Lambungmangkurat

Putri Khusnul Amriani, Journal Sosialisasi Pendidikan Sosiolog, Analisis Faktor Penyebab Rendahnya Tingkat Pendidikan Di Lingkungan Ii Patommo Kelurahan Arawa Kecamatan Watang Pulu Kabupaten Sidrap, Fisip Unm

Sarfa Wassahua, Analisis Faktor-Faktor Penyebab Anak Putus Sekolah Di Kampung Wara Negeri Hative Kecil Kota Ambon, Vol.1, No.2, Desember 2016

Lida Putri, Skripsi, Faktor Penyebab Rendahnya Tingkat Pendidikan Masyarakat Nelayan Di Lingkungan Iii Kelurahan Hajoran Kecamatan Pandan Kabupaten Tapanuli Tengah, 2020, Universitas Sumatera Utara.

Sintia Anjelita, Skripsi, Faktor-Faktor Yang Mempengaruhi Rendahnya Pendidikan Anak, 2019, Universitas Andalas

Sirozi, M.Ph.D.2005. Politik pendidikan dinamika Hubungan antara kekuasaan dan praktik pendidikan.

Visi misi kabupaten Demak 2021-2024

Https://Infopemilu2.Kpu.Go.Id/File/Dok/Calon Bersama/Calon Bersama 50389170103 Eistianah Dan Ali Makhsun.Pdf

https://jatengprov.go.id/beritadaerah/ayo-sekolah-kembali-tuntaskan-penanganan-anak-tak-sekolah https://dindikbud.demakkab.go.id/

https://halosemarang.id/sediakan-beasiswa-pemkab-demak-ajak-ats-kembali-bersekolah

$\begin{array}{lllll}\text { Provinsi Jawa } & \text { Tengah } & \text { Dalam } & \text { Angka } & \text { 2021/ }\end{array}$

https://jateng.bps.go.id/publication/2021/02/26/c5709cd0419788a55827d58f/provinsi-jawa-

tengah-dalam-angka-2021.html

Demak Dalam Angka 2021/ https://demakkab.bps.go.id/

https://dindikbud.demakkab.go.id/index.php/2020/12/16/wajibkan-belajar-12-tahundindikbud-kab-demak/ 
Dewi Sintha, Hardi Warsono, Agustin Rina Herawati, Retno Sunu Astuti \& Teuku Afrizal, Strategi

Hasanah, Y. M., \& Jabar, C. S. A. (2017). Evaluasi program wajib belajar 12 tahun pemerintah daerah Kota Yogyakarta. Jurnal Akuntabilitas Manajemen Pendidikan, 5(2), 228-239.

Aulia, S. (2013). Desentralisasi Kebijakan pendidikan (studi tentang pelaksanaan wajib belajar 12 tahun di kota surabaya pada tingkat pendidikan menengah dan kejuruan). Jurnal Politik Muda, 2(1).

Wardani, W. K., Astuti, P., \& Harsasto, P. (2015). Implementasi Program Wajib Belajar 12 Tahun di Provinsi DKI Jakarta (Studi Kota Administrasi Jakarta Timur). Journal of Politic and Government Studies, 4(2), 371-388. 